\title{
As Táticas e Estratégias de Enfrentamento da Violência entre Jovens em Timon-MA
}

\author{
Raquel da Silva Rodrigues ${ }^{1}$ \\ ${ }^{1}$ Universidade Estadual do Piauí, PI, Brasil.
}

\author{
Patrícia Rocha Lustosa ${ }^{1}$ \\ ${ }^{1}$ Universidade Estadual do Piauí, PI, Brasil.
}

\begin{abstract}
Resumo: O presente artigo trata de uma pesquisa realizada a respeito da violência na perspectiva de jovens bem como as maneiras que encontram para lidar com o contexto local, visto que a área está localizada no município de Timon-MA, uma zona de vulnerabilidade social. Para a produção de sentidos foi utilizada a prática da etnografia por meio do mapeamento do campo, estabelecendo vínculos e relações com os grupos de adolescentes, e dentre alguns os que tiveram maior contato foram os informantes da pesquisa. Esta foi elaborada no período de um mês, a fim de investigar de maneira singular e subjetiva a realidade do ambiente que os jovens estavam inseridos e as circunstâncias que nele estão implicadas. Para a análise das informações produzidas, foram adotadas como modelo as práticas comuns ou ordinárias de Michel de Certeau que se constituem em estratégias ou táticas que moldam a vida cotidiana. Somadas a essas informações, contribuem na análise os dados estatísticos da violência a partir dos estudos de Waiselfisz e Cerqueira et al., bem como em relação à situação de vulnerabilidade no contexto social por Abramovay et al. Considerando essas práticas como produtos da ordem socialmente imposta, os jovens revelaram na pesquisa uma reapropriação do cotidiano através de novas maneiras de fazer, abrindo espaço para uma nova arte de viver no mundo contemporâneo.
\end{abstract}

Palavras-chave: Juventude, Violência, Práticas Cotidianas.

\section{Tactics and Strategies for Coping with Youth Violence in Timon-MA}

Abstract: This is a research on violence according to youngsters' perspective as well as on the strategies they find to handle their local context, located in Timon-MA, an area of social vulnerability. Ethnographic practice was used for the production of meanings, by means of field mapping, establishing links and relations with groups of teenagers; those who had more contact were the informants of the research. This research took a month and aimed to investigate in both singular and subjective ways the reality of the environment in which the youngsters were and the circumstances that this context implied. For the analysis of the collected data, Michel de Certeau's common or ordinary practices were adopted as a model; these practices are strategies or tactics that shape everyday life. Waiselfisz and Cerqueira et al.'s statistical data on violence as well as Abramovay et al.'s studies on the situation of vulnerability in the social context contributed to this analysis. By considering these practices as products from the socially imposed order, the youngsters revealed in the research a re-appropriation of everyday life through new ways of doing, opening space for a new art of living in the contemporary work.

Keywords: Youth, Violence, Daily practices. 


\title{
Las Tácticas y Estrategias de Enfrentamiento de la Violencia entre Jóvenes en Timon-MA
}

\begin{abstract}
Resumen: El presente artículo se trata de una investigación realizada sobre la violencia en la perspectiva de los jóvenes, así como las maneras que encuentran para lidiar con el contexto local, ya que el área está ubicada en el municipio de Timon-MA, una zona de vulnerabilidad social. Para la producción de sentidos se utilizó la práctica de la etnografía por medio del mapeo del campo, estableciendo vínculos y relaciones con los grupos de adolescentes, y entre algunos los que tuvieron mayor contacto fueron los informantes de la investigación. Ésta fue elaborada en el período de un mes, a fin de investigar de manera singular y subjetiva la realidad del ambiente que los jóvenes estaban insertos y las circunstancias que en él están implicadas. Para el análisis de las informaciones producidas, se adoptaron como modelo las prácticas comunes u ordinarias de Michel de Certeau que se constituyen en estrategias o tácticas que moldean la vida cotidiana. En el análisis de los datos estadísticos de la violencia a partir de los estudios de Waiselfisz y Cerqueira et al., así como en relación a la situación de vulnerabilidad en el contexto social por Abramovay et al. Considerando estas prácticas como productos del orden socialmente impuesto, los jóvenes revelaron en la investigación una reapropiación de lo cotidiano a través de nuevas maneras de hacer, abriendo espacio para un nuevo arte de vivir en el mundo contemporáneo.
\end{abstract}

Palabras clave: Juventud, Violencia, Practicas Cotidianas.

O Projeto Educativo Mãos Dadas surgiu da ideia de um missionário colombiano Pe. Armindo Dinis que regressou a Timon em 1987 e questionado pela realidade encontrada na comunidade, idealizou um projeto em que as crianças não justificassem seus caminhos pela falta de oportunidade, pelo abandono ou miséria local. Com o apoio da Prefeitura Municipal de Timon, essa comunidade recebeu investimentos para a construção de uma escola, assim como subsídios para contratação de professores, funcionários e de recursos materiais.

Atualmente, a comunidade que está localizada no Parque Alvorada, uma região de vulnerabilidade social. Para Abramovay, Castro, Pinheiro, e Martinelli (2002), essa vulnerabilidade é um produto negativo da relação de disponibilidade dos recursos dos atores e à falta de acesso às oportunidades sociais, econômicas e culturas que são deveres do Estado e da sociedade. A maior parte da população enfrenta situações de violência, principalmente jovens e adolescentes, que têm seus direitos fundamentais violados. Kaefer, Traesel e Ferreira (2010) explicam a questão da violência não pode ser vista como de ordem reducionista que ora coloca a culpa na criança, ou na família, mas sim como multicausal, em que se leva em consideração os demais elementos que perpassam a história de vida do sujeito.
De acordo com Guareschi, Reis, Huning e Bertuzzi (2007), é preciso considerar os aspectos que são inerentes ao indivíduo e os que são referentes ao contexto social. Os autores explicam que a partir de algumas observações como falta de acesso às informações por parte das pessoas, ou aos serviços básicos de atenção há o aumento da vulnerabilidade dada a combinação de arranjos sociais e políticos desfavoráveis. Esses fatores dificultam ainda a garantia dos exercícios de cidadania e uma posição de desvantagem frente às condições de promoção dos direitos.

Sendo assim, o artigo trata-se de uma pesquisa destinada a caracterizar a violência de acordo com as concepções dos adolescentes bem como conhecer as maneiras que eles utilizam para lidar com esse tipo de situação por meio de assuntos que permeiam o dia a dia. Dentre os principais conteúdos estiveram presentes circunstâncias ligadas à sexualidade, gravidez na adolescência, violência sexual, racismo, problemas ligados ao sistema familiar, homofobia e bullying. Todos esses aspectos apontados despertavam a curiosidade dos jovens e se constituíam como uma multiplicidade de estruturas emaranhadas umas às outras.

Dessa forma, foi feita a etnografia com o intuito de produzir as informações dos jovens a respeito da violência para posterior análise, adotando como 
referência as práticas cotidianas de Certeau. Assim, é importante ter conhecimento de alguns conceitos que o autor explica sobre os elementos do cotidiano e finalizando o artigo, apontamos algumas considerações sobre as práticas ordinárias a partir dos informantes como também abrindo espaço para novas artes de fazer o cotidiano.

\section{Insígnias da violência e adentrando o campo}

A violência tem sido uma das maiores preocupações não somente no Brasil, mas também nas Américas e no mundo (Waiselfisz, 2015). Essa inquietação está presente em todas as regiões do país e não tem atores sociais permanentes nem causas facilmente detectáveis.

O autor ainda explica que há um crescimento nos indicadores da violência no mundo, como homicídios, conflitos relacionados a etnia, religião e raça, e questões envolvendo a criminalidade; e nas últimas décadas o conceito de violência vem sendo ressignificado e englobando a violência intrafamiliar contra as mulheres, contra crianças, a violência contra os grupos, a violência na escola, que estão transitando do âmbito privado para a esfera pública.

As causas externas de mortalidade - que são independentes de causas organísmicas, envolve mortes no trânsito, homicídios e suicídios - são as principais entre crianças e adolescentes no país, e dentre os fatores, o mais comum é o homicídio. Para Waiselfisz (2015), essa taxa vem crescendo de forma exorbitante nas últimas décadas: em 1980 os índices de homicídio representavam $6,7 \%$ do total de óbitos na faixa etária de 0 a 19 anos de idade e em 2013 esse índice aumentou para $29,0 \%$, já as causas naturais de mortalidade - indicativas de problemas no organismo devido a doenças ou envelhecimento - representavam $7,8 \%$.

Nos últimos anos, as causas naturais têm diminuído significativamente enquanto as causas externas têm um crescimento contínuo. Como consta na análise feita por Cerqueira et al. (2017), os dados do Censo do Instituto Brasileiro de Geografia e Estatística (IBGE) de 2015 mostram que dentre as mortes associadas às causas externas, as mais frequentes os homicídios, os acidentes de trânsito, quedas acidentais, suicídios tem ocupado um papel de destaque, de valor negativo, principalmente em jovens do sexo masculino. $\mathrm{Na}$ faixa etária de 15 a 29 anos, as mortes são mais preponderantes entre o período de 20 a 24 anos. Uma das explicações para as mortes nessa faixa etária é que na passagem da adolescência para a vida adulta os jovens se envolvem mais em acidentes de transporte, sendo mais relevantes que nos outros períodos.

Os autores ainda complementam que nos dados do Atlas da Violência, a mortalidade masculina de 15 a 29 anos correspondeu a $47,8 \%$ do total de óbitos. Ao considerar apenas os homens entre 15 a 19 anos, o indicador de mortalidade corresponde a $53,8 \%$ do valor total, mostrando uma naturalização do fenômeno da violência no contexto da segurança pública brasileira.

Waiselfisz (2015) aponta que dentre as regiões com elevadas taxas de homicídio estão o Nordeste, com índice de 73,3 por mil adolescentes e o Centro-Oeste, com 65,3 por mil adolescentes, já as menores são encontradas no Tocantins, Santa Catarina e São Paulo, onde a menor é no Tocantins com 11,4 homicídios por mil adolescentes. Comparando os índices de todas as regiões, o Nordeste apresenta um crescimento de $182,0 \%$, logo depois vem a região Norte com $108,0 \%$ e a Centro-Oeste com 80,8\%. A região Sul apresenta um crescimento moderado com 37,5 e o Sudeste mostra uma caída com $25,6 \%$.

Percebe-se que as causas externas de mortalidade na faixa etária de 16 e 17 anos vem aumentando no decorrer dos anos, ao contrário das causas naturais que decaem de forma contínua, que de acordo com Waiselfisz (2015) esse declínio nas últimas décadas é decorrente da melhoria do sistema de saúde, progresso na qualidade educacional, melhores condições de vida da população, sistema de saneamento básico, ao contrário das causas externas que crescem na maior parte das vezes pela mortalidade dos jovens e adolescentes por meio da violência homicida.

$\mathrm{Na}$ análise feita por Cerqueira et al. (2017) no Atlas da Violência, entre os anos de 2005 a 2015, as maiores diminuições nas taxas de violência e homicídio aconteceram no Espírito Santo, Paraná e Alagoas. Por outro lado, houve um aumento substancial nos últimos cinco anos nos estados de Sergipe (+ 77,7\%), Rio Grande do Norte (+ 75,5\%), Piauí (+ 54,0\%) e Maranhão (52,8\%), com taxas de homicídio acentuadas e preocupantes.

Em relação às taxas de violência no município de Timon, as últimas pesquisas da Datasus, em 2013, indicam que os índices da cidade se encontram próximos às estimativas nacionais. Como consta no site, de acordo com Deepask (2016), a título de exemplificação, a taxa de assassinatos de homens por 100 mil habitantes da região corresponde a $43,26 \%$ enquanto a média nacional é de 50,58 por 100 mil habitantes. 
Isso significa que a diferença da taxa da região para a taxa nacional é de $7,42 \%$. Quanto às mulheres, essa diferença é de $1,14 \%$, visto que 3,61 representa o índice do município e 4,45\% é o índice nacional. Percebe-se que há a prevalência de morte maior do sexo masculino, pois os homens estão mais envolvidos em atividades de alta periculosidade e que correm risco.

Esses dados indicam que a violência é crescente em território nacional. É comum ver nas mídias televisivas, principalmente programas policiais, reportagens a respeito da violência, em sua maioria, a criminalidade por exercício de jovens e adolescentes. Embora seja uma causa social emergente, é preciso analisar os fatores que estão relacionados a ela, pois não se trata de um fenômeno simples.

Evita-se encerrar a violência numa única definição sem considerar suas especificidades e peculiaridades históricas. Assim, durante a experiência de estágio no Projeto Educativo Mãos Dadas, foi possível observar como é o cotidiano de jovens que estão numa área de vulnerabilidade social, que mesmo com os baixos indicadores sociais, há na equipe de profissionais da comunidade escolar potência e implicação no trabalho, a transformar a realidade local, visto que o objetivo do projeto não é apenas educacional, mas também trata de recuperar os direitos e cidadania dos jovens que se encontram em situação de risco social, notadamente esquadrinhado pelo mapa da violência.

O primeiro contato com a escola se deu através de uma visita para conhecer o espaço, o público que a comunidade escolar abrange e seu funcionamento. A habitação de um território faz parte do processo de pesquisa, tal como mostram Passos, Kastrup e Escóssia (2014), é um processo de aprendizado no sentido de movimento em transformação. A partir daí o processo de habitação é construtivo colocando o cartógrafo numa posição de aprendiz. Embora de início o campo seja um elemento estranho ao pesquisador, é preciso que tenha uma receptividade.

A escola tem um território amplo, dispondo de uma quantidade grande de salas, ainda que algumas delas não fossem utilizadas, assim como era possível encontrar no ambiente, lugares propícios a realizar atividades de diversos temas, como por exemplo, de natureza lúdica, artística, desportiva, dentre outras. Os autores explicam que a experiência de conhecer o campo serve para o aprendizado do pesquisador, pois dá abertura afetiva e engajamento ao território, penetrando o campo na perspectiva de composição e con- junção de forças. Também fazia parte da área escolar o quadro de funcionários, composto por professores, secretárias e uma equipe de apoio que trabalham em prol da segurança, qualidade e melhor educação para os jovens alunos.

Após a exploração do campo, fui apresentada à sala que realizaria as atividades através da prática etnográfica. Ao entrar na sala, percebi que alguns alunos olhavam com estranhamento e pouco abertos para o diálogo, que é compreensível, em se tratando de uma pessoa diferente do convívio deles, ao passo que outros, em sua maioria, se mostraram bem receptivos e acolhedores, interagindo e transparecendo curiosidade pelo que tinha a oferecer com meu trabalho, que para Passos et al. (2014), o aprendiz cartógrafo tem uma tendência de receptividade mais alta por mostrar uma característica mais aventureira ou confusa nas demarcações de território. A proposta das atividades consistia em trabalhar com temas que seriam sugeridos por eles, como forma de discutir assuntos a partir do interesse dos alunos, dando abertura para uma relação mais interativa e comunicativa do que apenas expositiva, determinando também os critérios éticos da experiência em que os relatos compartilhados seriam mantidos sobre a forma de sigilo e em nenhum momento os alunos seriam expostos aos demais.

Posteriormente ao estágio foi utilizada a prática etnográfica com um grupo de adolescentes da escola que se dispuseram a relatar sobre a violência, a fim de saber dos jovens o sentido da violência e estratégias que encontram para lidar com a mesma na região. Esse tipo de modelo de pesquisa corresponde ao método qualitativo, que segundo Lustosa (2013) permite que o sujeito apresente suas opiniões sobre determinado objeto de investigação de maneira singular e subjetiva. As informações foram produzidas com relatos dos adolescentes sobre o tema. A autora ainda comenta que a entrevista em profundidade tem guardado em si a formação da sua autoimagem e o modo como se estabelecem as relações sociais.

As informações produzidas foram gravadas em áudio a fim de captar maiores detalhes as palavras e expressões enunciadas e transcritas na íntegra, com duração de aproximadamente quarenta minutos cada uma. Segundo Bourdieu (2011), nesse modelo de entrevista deve ter um acordo de confiança entre o pesquisador e o interlocutor, mudando muitas vezes, as referências de locais e assegurando o sigilo da pesquisa. $\mathrm{O}$ autor ainda aponta algumas sugestões a res- 
peito da transcrição das entrevistas, como a postura corporal, as mímicas, os silêncios, os risos, os olhares e a entonação de voz do informante são importantes para a análise e dizem respeito a muita coisa do informante. Assim, o pesquisador deve transcrever tudo o que foi dito e sentido durante a entrevista.

Os informantes da pesquisa foram oito jovens adolescentes, sendo quatro do sexo masculino e quatro do sexo feminino que foram estudantes da instituição Projeto Educativo Mãos Dadas, localizado no município de Timon. Eles consentiram de forma livre e esclarecida, como previsto pelo Comitê de Ética em Pesquisa da Faculdade de Ciências Médicas da Universidade Estadual do Piauí (CEP/CCS/UESPI). Como todos os adolescentes eram menores de idade, foi solicitada a autorização prévia dos pais ou responsáveis. As informações foram produzidas por meio da etnografia que ocorreu no mês de junho de 2016, aos sábados pela manhã, contando de três encontros em trios e duplas que ocorreram de acordo com a compatibilidade e disponibilidade dos jovens para comparecer até a escola.

Embora pudesse ocorrer a enunciação de algum conteúdo que desviasse do tema central da pesquisa, toda palavra pode remeter a um processo de subjetivação e de acordo com Lustosa (2013) é importante ouvir atentamente o que o informante diz, pois ele está por vontade própria requerendo uma fala ou escuta.

Alguns contratempos ocorreram ao longo do percurso, como a dificuldade para marcar os encontros na escola que em pouco tempo entrou em processo de reforma na estrutura interna sendo inviabilizada a realização da produção de sentidos com alunos no local. Por sugestão da coordenadora da escola, a Paróquia Menino Jesus de Praga - onde o padre idealizador do Projeto Educativo Mãos Dadas celebra as missas que estariam disponíveis para proceder os encontros.

Nos primeiros encontros a violência foi o principal aspecto relatado. Para Abramovay et al. (2002), o conceito de violência abarca uma multiplicidade de atos violentos em que devem ser analisadas as suas significações de acordo com as normas, condições e contextos sociais, que variam de um período para outro. A respeito do significado de violência, alguns jovens relataram que o ato ou a prática da violência era "uma perda de tempo" ou "falta de mentalidade" de quem executa, por se tratar de algo banal que não tra- ria vantagens ou benefícios para nenhuma das partes envolvidas. Para Certeau (2008, pp. 153-154), "a arte de dizer" se alterna e implica na "arte de fazer", pois o conteúdo do relato pertence à arte de fazer golpe: ele é o desvio por um passado que produz efeitos, criando um novo arranjo do conjunto. Por isso, era importante atentaram ao fato de a violência ser considerada prática desenvolvida na sociedade há muito tempo, que é caracterizada por ser criminosa e ilegal ou como, na linguagem dos jovens "algo que eu faço com o outro que eu não quero que faça comigo".

Retrataram ser um aspecto muito recorrente no bairro, pois apresenta os maiores indicativos de periculosidade do município e as pessoas, cada vez mais, vivem amedrontadas com as informações e notícias que circulam sobre a violência. É preciso compreender as formas que as práticas cotidianas se estruturam para modificar os espaços que elas se encontram. De acordo com Certeau (2008, p. 92), as ações do tipo tático ${ }^{1}$ como - ler, habitar, falar - se modificam e se ampliam provocando modificações também no sistema estratégico. Os informantes mostravam uma preocupação ao abordar o tema ao passo que consideravam importante tecer comentários sobre, pois talvez relatando sobre, a reflexão possibilitaria a criação de estratégias para modificar o paradigma atual da área.

Os tipos de violência mais comuns na região envolvem principalmente situações de agressões física, verbal e psicológica com mulheres e às características nela envolvidas (questões de sexualidade, gênero, etnia). Destacaram também os tipos de violência recorrentes no meio social, que está diretamente ligado com o sistema familiar, como também algumas questões de preconceito e homofobia e à prática do bullying.

\section{Em busca de um lugar no espaço}

Um dos principais temas de maior interesse dos alunos estava relacionado às questões sobre sexualidade, gravidez na adolescência e métodos contraceptivos. Esse momento foi importante porque pude observar quais temas eram despertavam a curiosidade dos jovens e qual seria o significado que cada assunto teria para eles, segundo Certeau (2008, p. 142), para que haja cultura, não basta ser autor das

${ }^{1}$ Para o autor, as táticas (p. 102) são ações calculadas e determinadas pela ausência de um próprio, é uma ideia que remete à interioridade, em que o sujeito joga com o que é imposto, sendo capazes de manipular, utilizar e alterar. São ações divergentes que originam diferentes maneiras de fazer. 
práticas sociais; é preciso que essas práticas sociais tenham significado para aquele que as realiza. É através da atividade humana que a cultura se expressa, sem que não necessariamente seja reconhecida como tal, mas que tenha uma significação para o praticante.

Ainda a respeito do autor, outra observação feita foi a respeito das práticas dos alunos, quando alguns apresentavam os modos de relação através de estratégias ${ }^{2}$ e táticas, com relações de poder e dominação, e dominante sobre dominado. Ao mesmo tempo em que uns adolescentes demonstravam a importância de ouvir o que o outro tinha a dizer, articulando sugestões e comentários, outros manifestavam aversão ao que estava sendo exposto, negligenciando a presença das pesquisadoras através da recusa em trocar informações ou pela invenção de outra maneira de fazer que não fosse relacionada aos encontros, como Certeau (2008, pp. 41-42) chama de "manobras" da vida cotidiana, em que a tática, esses modos de proceder e as astúcias de consumidores compõem, no limite, a rede de uma "antidisciplina".

Considerando a fase de desenvolvimento que os alunos se encontram, a maior parte vivenciando a sexualidade, o tema foi tocante para alguns e como ainda é considerado tabu ou polêmica, outros não se sentiam à vontade para compartilhar suas experiências com os demais, preferindo, em alguns casos, me chamar reservadamente para esclarecer suas dúvidas. De acordo com Certeau (2008, p. 13), essa prática cotidiana ${ }^{3}$ do homem comum é uma ação que pode se camuflar num emaranhado silencioso e sutil da mesma forma que é um método de desenvolver a maneira própria como saída da condição imposta pelo sistema de consumo, a chamada prática criativa.

Do mesmo modo, percebia a inquietação de jovens ao ver que os colegas não estavam respeitando o momento, considerando a discussão como um passatempo ou um estágio para a hora do intervalo que já estaria bem próxima. Também ocorria de muitos jovens falavam simultaneamente, por se tratar de um grupo grande, composto por trinta e sete alunos, o nível de atenção era baixo. O autor ainda explica que é importante compreender o uso dessas táticas e onde elas podem ir, pois dentro da prática cotidiana significa entender como ela age para determinado fim, podendo originar uma nova maneira de fazer.

Através de uma nova invenção cotidiana, como forma de facilitar o diálogo, uma prática foi adotada: quem quisesse expor sua opinião deveria esperar que o outro terminasse sua fala. Após isso, um aluno se sentiu mais confortável com o ambiente e decidiu partilhar juntamente aos demais seus conhecimentos sobre o conteúdo. A partir dessa arte de fazer, foi possível estabelecer ajustes à prática local, através da articulação com os saberes dos alunos, produzindo uma cultura pedagógica na comunidade escolar.

A relevância das discussões estava no significado que era atribuído à nomenclatura de sexualidade, sendo diretamente relacionada com o sexo e com relacionamento amoroso. Este último sendo mais popularmente conhecido como "ficar", que foi proferido muitas vezes na fala dos jovens.

Nos discursos dos jovens estavam presentes questões de contexto histórico, marcadas por usos ${ }^{4}$, com palavras e enunciados de cunho religioso e cultural. Essas "marcas de uso" são relativas às operações que foram objeto, situações moldadas do enunciado ou da prática em que os procedimentos dessa prática se tornam instrumentos manipuláveis pelos usuários (Certeau, 2008, p. 82). Durante a prática, alguns jovens citaram o papel da mulher nos relacionamentos e no matrimônio, pois para uns o namoro representava uma preparação para o casamento e a relação sexual só deve acontecer depois de firmada a união do casal. Imediatamente, surgiram os argumentos contrários, principalmente dos garotos, que exprimiam não acontecer daquela forma, considerando uma "bobagem" as mulheres pensarem dessa maneira nos tempos atuais e que a relação sexual pode acontecer a qualquer momento desde que o casal entre em acordo.

Em seguida, alguns alunos já se mostravam cansados com a discussão, preferindo que se desse por encerrada e desejando a escolha do tema seguinte. Nesse momento, uma aluna parecendo estar angus-

\footnotetext{
${ }^{2}$ Certeau denomina de "estratégias" as ações e concepções que supõem a existência de um lugar próprio, de um poder que nele é instituído que são capazes de produzir e impor. O autor chama de estratégia (p. 99), "o cálculo (ou a manipulação) das relações de forças que se torna possível a partir do momento em que um sujeito de querer e poder (uma empresa, um exército, uma cidade, uma instituição científica) pode ser isolado".

${ }^{3}$ As práticas cotidianas, de acordo com Certeau (2008, p. 13) são práticas iguais e padronizantes, desenvolvidas em circunstâncias e ocasiões que definem os modos de usar as coisas e/ou as palavras.
}

${ }^{4} \mathrm{O}$ autor explica que o uso é o ato que provoca um efeito sobre a ação, como por exemplo, o ato de falar. 
tiada e confusa com o debate, opta por me procurar em particular explicando que queria falar mais sobre o assunto, mas não conseguia encontrar palavras para expressar o que estava sentindo. É o que se chama de um "saber não sabido". Trata-se de um saber sobre o qual o sujeito não reflete, sendo, portanto, incapaz de apropriá-lo. É um saber que está no local, mas que o sujeito não pode se apossar desse saber-fazer (Certeau, 2008, p. 143). Esse tipo de saber não é proprietário do sujeito e não ficam conscientes àquele quem o pensa, restando somente a impressão do debate apenas como os fragmentos e efeitos desse saber, dessa astúcia e tática análoga à arte.

No encontro seguinte, o tema retratado foi sobre gravidez na adolescência. Ao chegar na sala, fui bem recepcionada por alguns alunos que mostraram ter sentido falta e estavam ansiosos pelo debate da semana. A partir desse relato, pude observar que já fazia parte da realidade dos jovens, da coletividade do território; coletividade esta entendida não somente à organização formal da sociedade, mas também como objetos que compõem a realidade: coisa e o estado da coisa. Passos, Kastrup e Escóssia citam Foucault para explicar que a realidade é resultado dos modos de dizer e ver um determinado momento histórico. A realidade dos jovens parecia estar sendo apontada aos poucos, à medida que cada vez mais eles pareciam interessados nas discussões e parecendo que tinha algum valor significativo para eles.

No início da discussão, uma aluna disse esse debate faria uma ligação direta com o tema da semana anterior, pois não podia deixar de falar sobre gravidez na adolescência sem falar sobre sexualidade e sexo.

O principal aspecto trazido na fala da jovem foi a respeito do que a gravidez pode representar na vida de uma pessoa que está vivendo a sua juventude, no ápice de sua sexualidade e sua adolescência, um momento de descobertas e experiências, de aproveitar as oportunidades, "de curtir muito a vida"; para ela seria uma responsabilidade muito grande que talvez não pudesse arcar. Certeau (2008, p. 69) explica que a linguagem ${ }^{5}$ deve ser levada a sério, pois define nossa historicidade, nos supera e envolve sobre o mundo ordinário, e que nenhum discurso pode "sair dela" e colocar-se à distância para observá-la e dizer o seu sentido. Dessa forma, a linguagem deve ser apreendida como um conjunto de práticas onde a própria pessoa se acha implicada.

Em seu discurso, a jovem mostrou que os sentidos de uma gravidez seriam muito amplos, posto envolver questões de instâncias pessoais, familiares e sociais, então a melhor forma de evitar seria através da prevenção, com a utilização dos métodos contraceptivos. Esses métodos não somente previnem a gravidez bem como são meios de precaução, evitando que os indivíduos fiquem vulneráveis às doenças sexualmente transmissíveis, um risco que pode comprometer tanto o projeto de vida quanto a própria vida dos adolescentes.

Após a sua fala, as opiniões de apoio surgiram, constatando primeiramente que para a jovem teria o momento de negação, de não aceitar o que está acontecendo e depois vêm os questionamentos, os porquês de estar acontecendo com ela e, por fim, a família. Para a família seria complicado porque causaria um impacto muito grande para os pais receber a notícia da gravidez de uma filha. Uma jovem contou que em primeira instância seria uma atitude "totalmente compreendida”. De acordo com Certeau (2008, p. 40), a forma como uma representação é mostrada, seja por meio do código da promoção por pessoas que não produziram, não indica como ela é; é preciso que se analise a maneira como ela é manipulada pelos praticantes que não a fabricaram.

Nesse sentido, a perspectiva certeuniana evidencia que é preciso analisar as maneiras de fazer ${ }^{6}$, de investigar como as pessoas utilizam esses produtos impostos por um lugar de poder. Essa maneira de fazer pode assumir um lugar de poder ou de um sujeito humano totalmente compreendida -, mas que, ao mesmo tempo em que é compreendida, pode gerar depois a rejeição no sistema familiar, em que o não consentimento de uma gravidez pode gerar vários tipos de agressão, principalmente psicológica e física.

A realidade da violência estava bem próxima na localidade e essa realidade parece fazer mais sentido quando as atitudes de hostilidade são direcionadas às

\footnotetext{
${ }^{5}$ Nesse aspecto, o autor faz forte crítica ao Wittgenstein, que traz uma "linguagem ordinária” (p. 69), desconsiderando a historicidade dessa prática, mantendo essa historicidade no presente sem recorrer ao passado do historiador.

${ }^{6}$ As maneiras de fazer são estilos de ação que obedecem a outras regras que não aquelas da produção de consumo oficiais, dando origem a novas "maneiras de utilizar" a ordem imposta. O autor demonstra (9p. 92-93) que "há outras 'maneiras de fazer', 'maneiras de utilizar' que se tecem em redes de ações reais que não são e não poderiam ser mera repetição de uma ordem social preestabelecida”, como por exemplo, caminhar, ler, produzir, falar.
} 
mulheres, que parecem ser o alvo proeminentemente fácil dessas situações. Durante os encontros das entrevistas de pesquisa, os jovens aparentavam sensibilizados e certa comoção com os últimos acontecimentos sobre o assunto não só com as situações de violência que são frequentes na localidade, mas também mostravam preocupação e afetados a respeito da violência que envolve todo o país, pois constituía uma prática cada vez mais distante de ser extinta.

Durante os diálogos, algumas informantes conversavam a respeito do estupro coletivo de uma jovem de dezesseis anos no Rio de Janeiro. Segundo o site El País Brasil, um vídeo em que supostamente uma garota estava sendo violentada sexualmente por vários rapazes estava sendo compartilhado nas redes sociais e chegou até o Ministério Público do Rio de Janeiro depois de várias denúncias anônimas. Nesse vídeo, a garota menor de idade estaria sendo estuprada por mais de trinta homens. A repercussão do acontecido foi de grande impacto para a sociedade em geral, e as adolescentes que comentavam sobre o caso retomaram esse aspecto durante o momento de entrevista.

No discurso das jovens foi destacada a não aceitabilidade do que havia acontecido classificando como uma atitude imperdoável e injustificável, pois nenhum homem poderia abusar sexualmente de uma mulher sem o seu consentimento. Ainda contavam que no meio social se cultua a ideia de que "usou roupa curta, tá pedindo para ser estuprada". De acordo com Certeau (2008, pp. 84-85), os jogos específicos de cada sociedade dão espaço ao lugar onde os lances são proporcionais às situações. As práticas cotidianas são definidas como manipulações a um sistema da língua ou da ordem estabelecida. Sendo assim, as informantes diziam ser comum observar nos discursos das pessoas, principalmente no pensamento dos homens, que o fato de a mulher andar com determinada vestimenta, ela pode ser violentada.

Além de a mulher "pedir para ser estuprada", o fato de supostamente estar drogada também supõe ser motivo para a violência sexual. Nesse sentido, a mulher é tida como frágil e incapaz, privando-se de gozar da sua liberdade perante o povo. As adolescentes repetiam que as mulheres eram livres para fazer o que quisessem por mais que a ordem socialmente imposta julgasse como errado.

Um ponto de vista semelhante a isso se deve à cultura do machismo, característica presente no discurso das pessoas, que é por tantas vezes reforçado nas práticas e atitudes do dia a dia. A supervalorização dos atributos masculinos em detrimento dos femininos caracteriza a atitude machista. De acordo com as adolescentes, os homens nutrem uma crença de que são superiores às mulheres, que têm propriedade sobre elas, podendo agir da maneira como lhes for mais conveniente.

Ainda é comum que os homens sejam mais valorizados que as mulheres, uma prática cotidiana, mas as jovens mencionavam a partir disso as mulheres podem mudar esse panorama por meio de novas maneiras de fazer. Certeau (2008, p. 69) define que essas maneiras de fazer são do tipo tática, em que a prática que parta do princípio que é diferente do que é imposto. Dessa forma, as táticas produzidas pelas mulheres é a persistência na luta pela igualdade de gêneros, já que elas devem ter os mesmos direitos que os homens.

Em algumas falas também foi destacada que a incidência de violência é maior quando uma mulher é negra, da periferia e de orientação sexual que não corresponde ao padrão normalmente aceito pela sociedade. O preconceito que está arraigado no pensamento das pessoas encontra-se velado, assumindo uma condição estratégica de poder, que de acordo com Certeau (2008, p. 101) elabora sistemas e discursos totalizantes, capazes de articular um conjunto de lugares físicos onde as forças se distribuem - cultura dominante - se sobrepõe aos mais fracos, que assumem um lugar de fraco, sem lugar próprio, a prática tática.

A questão racial é igualmente apontada como preponderante no sistema social. As narrativas expunham que o racismo é presente no cotidiano das jovens, em situações vividas pelas próprias e que o preconceito é advindo geralmente de pessoas com tons de pele mais claro. Nessa perspectiva, ainda ressaltam a discriminação decorrente do racismo: determinada pessoa por ser negra é considerada inapta a fazer algo ou até mesmo proibida de relacionar-se com outra pessoa pelo fato de não ser da mesma etnia.

Além disso, o padrão social normativo branco instaura uma hegemonia de poder, onde os pobres são praticamente excluídos dos direitos de cidadania. As adolescentes discorriam sobre a exclusão que acontece com as pessoas de nível socioeconômico mais baixo, são tratados com indiferença, chamados de "miseráveis da população", segregados ou até desencorajados de permanecer no mesmo espaço que os brancos.

Os jovens concordaram que nesses casos é preciso compreender todos os aspectos que estão relacio- 
nados com a sexualidade, violência contra a mulher, situações de racismo um dos principais meios de enfrentar é pelo diálogo com quem possa ajudar. Ressaltam que atualmente existem grupos de apoio nas redes sociais para discutirem sobre essas questões, que de acordo com a concepção certeuniana, essa é uma reapropriação criativa do uso das coisas, em que os jovens utilizam de sua arte de fazer, capazes de contornar a submissão dos códigos que são impostos e estabelecidos pelo mundo contemporâneo.

\section{A família pelo prisma da produção de sentidos}

O tema família, sugerido pelos alunos, foi designado de uma forma diferente do que era esperado: com pincéis, cartazes, coleções, tintas, os jovens seriam divididos em grupos e teriam que exporem a representação da família, qual o significado que eles atribuem à definição do termo, a relevância do nome, através de frases, palavras ou desenhos. A apresentação da proposta pareceu embaraçosa para a maioria, ao revelar uma desorientação com a sugestão da atividade, que logo foi esclarecida através de direcionamentos e instruções de como o exercício poderia ser conduzido.

De acordo com Certeau (2008, p. 225), a escritura é a atividade concreta que consiste, sobre um espaço próprio, a página, em construir um texto que tem poder sobre a exterioridade da qual foi previamente isolado. É através desse exercício que o sujeito dispõe seu olhar sobre o campo e sobre ele mesmo através do fazer. De imediato, percebi algumas reações de bloqueio ou recusa em realizar a tarefa, que seja pela resistência ou mesmo por não conseguir simbolizar seus pensamentos, onde foi passado algum tempo com o papel em branco. A partir da lógica certeuniana, a página em branco a criança já tem o seu espaço e o executar é gerido através do querer próprio.

Decorrido algum tempo, começaram a surgir as primeiras palavras e frases: daí vem a construção do texto. $O$ autor explica que através dos processos gestuais e mentais, que o sistema vai sendo construído, em que a prática itinerante não é concebida, e sim produzida. Os cartazes já evidenciavam pontos como: amor, respeito, carinho, compreensão, união, diferentes composições, raiva, desunião, solidão, desigualdade e perdas. Após o término da produção dos cartazes, os jovens mostraram-se propensos a expor para a turma o que foi feito, embora muitos parecessem intimidados para apresentar aos demais o conteúdo do que construíram, talvez por uma preocupação de aprovação ou rejeição dos colegas.

Na produção dos cartazes, a principal característica escrita referia-se ao amor, conceito que é repassado pela família que tem importância para a constituição social do indivíduo. Certeau (2008, p. 226) aponta que são nesses jogos de escrituras que a produção de sentido é formalizada, remetendo a uma realidade que se distingue em mudar, ou seja, é pela escritura que os significados atribuídos são referentes aos sentidos que os jovens produzem acerca da sua realidade vivida.

A relevância da família está na construção e transmissão do conhecimento culturalmente organizado, além de desencadear processos evolutivos que são propulsores ou inibitórios do crescimento físico, mental, social e emocional dos sujeitos. De acordo com a fala dos jovens, a família desempenha um papel de muita relevância, porque é a partir dela que as pessoas aprendem como é conviver umas com as outras - sendo muitas vezes relações difíceis e conflituosas -, bem como aprendem a viver em comunidade.

Os valores de compreensão, fraternidade, paz e união também foram ressaltados nos cartazes, como conceitos que são repassados na sociedade, e de acordo com Certeau (2008),

A presença e a circulação de uma representação (ensinada como o código da promoção sócio-econômica por pregadores, por educadores ou por vulgarizadores) não indicam de modo algum o que ela é para seus usuários. É ainda necessário analisar a sua manipulação pelos praticantes que não a fabricam. Só então é que se pode apreciar a diferença ou a semelhança entre a produção da imagem e a produção secundária que se esconde nos processos de sua utilização (Certeau, 2008, p. 40).

Os jovens declaram em que esses valores são difíceis de serem mantidos nas relações com as outras pessoas, principalmente a união, já que as pessoas são diferentes umas das outras, devido à pluralidade de crenças, pensamentos e ações e muitas vezes não têm suas ideias e convicções sendo respeitadas.

Outro ponto destacado foi a respeito das diferentes composições familiares, em que além da família nuclear tradicional também existem as famílias compostas por padrastos, irmãos não nascidos em mesma família biológica, tios, avós e casais formados por pes- 
soas do mesmo sexo. Em relação a esse último, alguns jovens demonstraram interesse e curiosidade em aprofundar mais sobre o tema, pois ainda é um tabu na sociedade.

Os discursos pautavam na ideia de que a sociedade que é predominantemente heterossexual condena o que é diferente do padrão e, portanto, somente esse modelo deveria ser seguido. Por parte dos heterossexuais, há uma condenação contra os homossexuais e casais homoafetivos, considerando-os como "doentes", onde essa doença tem cura e pode ser tratada. As maneiras de fazer, os estilos de ação dos sujeitos reais obedecem a outras regras que segundo Certeau (2008, pp. 92-93) "é um espaço de jogo para maneiras de utilizar a ordem imposta do lugar ou da língua. Sem sair do lugar onde tem que viver e que lhe impõe uma lei, ele aí instaura a pluralidade e a criatividade", como consta na fala de outros adolescentes que embora ainda seja muito intolerante, os casais homossexuais estão ocupando um espaço na sociedade, disseminando alternativas aos produtos e regras do que normalmente está imposto.

\section{Relações sociais e apropriações heterodoxas}

Ainda sobre questões ligadas à homossexualidade, no debate também foi discutido sobre o preconceito que existe em relação à orientação sexual. De acordo com os adolescentes, essa é uma questão que ainda é muito complexa quando se trata principalmente da aceitação dos familiares. Segundo eles, a primeira atitude é de rejeição, que os pais nutrem a ideia de que "é uma mentira", "é apenas uma fase". Nesse aspecto, o conteúdo do relato também pode ser uma arte de fazer golpe, de fazer truques ou lances: um desvio para negação e redução do fenômeno, e que é preciso entender além do que se diz, posto o discurso provoca efeitos, é uma arte de dizer (Certeau, 2008, p. 154).

Na fala dos alunos, também tinha o sofrimento que a homossexualidade pode causar tanto para a família quanto para a própria pessoa e à possível marginalização e preconceito da sociedade, a responder mediante atitudes homofóbicas e agressivas. De acordo com Toledo e Teixeira (2013), uma das formas mais comuns de homofobia na família é a que o filho ou filha revelem a homossexualidade e a pós a revelação exigem que a pessoa se autoanule, excluindo-a de qualquer participação, reconhecimento ou representação de experiên- cia em outros grupos sociais. Essa atitude produz uma desumanização normativa e nega as necessidades afetivas, de vida cotidiana e social do filho homossexual, fazendo com que culmine uma ideia de não pertencimento do homossexual na sociedade.

Todos esses aspectos acarretam na segregação dos homossexuais do restante da população. Os informantes narravam que as pessoas não querem aceitar a forma como os gays, lésbicas e transexuais se comportam e agem na sociedade. De acordo com os relatos, as pessoas não entendem que a condição em que se encontram foi uma escolha deles, e embora "o modo de agir e maneira de pensar" seja diferente dos demais, isso não sendo motivo para desrespeito da sociedade.

Cada vez mais o público LGBT busca representatividade e reconhecimentos nos espaços, porém são hostilizados e rechaçados. As pessoas que ojerizam os homossexuais sustentam a ideia de que existe uma possibilidade de cura. A resposta que encontram para isso é por meio de atos violentos que são impulsionados pelo desejo de punir essas pessoas que desafiam as normas de gênero, quer seja por agressão física ou verbal. Uma delas comentava já ter ouvido insultos e comentários maldosos, principalmente na escola, por não se enquadrar nos padrões normativos e que ainda têm medo e receio de algum dia sofrer violência física por conta da sua orientação sexual.

A questão religiosa foi uma das saídas encontrada pelos jovens que sofreram algum tipo de ato de preconceito, relatando que somente a divindade maior é capaz de perdoar aqueles que cometem esse tipo de injúria. Essa característica esteve ligada aos conteúdos dos relatos e representam os produtos da cultura da sociedade. A partir dessas práticas os sujeitos se apropriam podendo transformar em outros produtos, em novas artes de fazer.

Uma das principais táticas encontradas pelos alunos é buscar informações sobre o que é a homossexualidade e formas de lidar com a situação. Outro recurso encontrado e relatado por alguns adolescentes foi e a experiência de realizar um projeto educacional que vários adolescentes saíam às ruas distribuindo $\mathrm{e}$ lendo panfletos informativos a respeito da violência contra os LGBTs, uma maneira de reapropriar as práticas culturais. A respeito da leitura, Certeau (200, pp. 48-49) denomina-as como sendo do tipo tática, pois a partir da tática de habitação, o leitor é capaz de transformar, reapropriar seu conteúdo e subtrair seu sentido, produzindo um novo texto, uma nova versão. 


\section{Bullying: da estratégia de dominação às maneiras de pensar o cotidiano}

As discussões também estiveram relacionadas a comportamentos agressivos e o bullying sabidamente não ocorre somente na escola, mas também em outros âmbitos sociais que esse tipo de violência está presente. Nesse aspecto, a metodologia de Certeau (2008, p. 81) descreve que o inconveniente do método e sucesso do mesmo, é retirar o contexto histórico que existe nas operações, nas circunstâncias de tempo e lugar para que as práticas científicas sejam exercidas no seu campo próprio, como foi confirmado pelos alunos ao mencionar que o debate seria uma alternativa para que eles pudessem expor sobre as particularidades de suas experiências com o tema.

Os alunos relatavam sobre a violência que acontece contexto escolar, que estava relacionada aos comportamentos desencadeadores de atos violentos em que o bullying se manifesta. As situações mais comuns ocorrem por meio de apelidos pejorativos, piadas referentes à aparência física, como também ridicularizam aqueles são mais tímidos e os que têm orientação sexual diferente da maioria.

Sobre esse último, os adolescentes relatavam ser a mais entre os estudantes e a que tem se reproduzido cada vez mais, tornando-as práticas comuns e generalizadas. Nessa perspectiva, os estudos sobre a invenção do cotidiano de Certeau (2008, p. 46), afirmam que nessas práticas só se encontra o homogêneo, reproduzindo o sistema ao qual pertence e deixando de fora as operações heterogêneas que fazem parte do cotidiano. Dessa forma, essas práticas não são adequadas para entender a complexidade, especificidades, elementos singulares que são histórica e socialmente construídos.

Os alunos expunham que geralmente as atitudes agressivas são dos alunos considerados ainda mais "machões", que ridicularizam os homossexuais, praticando o bullying homofóbico, como é chamando no contexto educacional. Esse tipo de violência acontece por meio de agressões verbais e/ou físicas, que segundo Dinis (2011), são apontadas a estudantes que não se adequam à heteronormatividade - norma que toma a heterossexualidade como universal e os discursos que permeiam a posição homossexual como desviante -, especificamente aos alunos que são gays, lésbicas, bissexuais. No entanto, nas suas vidas cotidianas, esses consumidores fazem diferenciados usos destes produtos e regras, no processo de desvio de suas táticas, pois como afirma Certeau (2008, p. 92), embora sejam relativas às possibilidades oferecidas pelas circunstâncias, essas "táticas" não obedecem à lei do lugar, sendo um tipo de operação que é capaz de utilizar, manipular e alterar.

Durante o diálogo dos alunos, foi destacado que os agressores utilizam do bullying e não pesam as consequências que a violência pode trazer para a vítima. Para Albino e Terêncio (2012), as primeiras consequências são baixa autoestima, agressividade, baixo rendimento escolar até a evasão e tendem a ficar mais graves, no sentido de que o agredido pode isolar-se socialmente como uma fuga contra as agressões ou ainda progredir para um transtorno psicológico, depressão, ideações suicidas e desejo constante de vingança. Dessa forma, é imprescindível ter o apoio da família e dos profissionais da escola, pois estes oferecem suporte e manejo para lidar com esse tipo de situação.

Também narravam que essas atitudes agressivas são decorrentes de outras relações sociais que a pessoa tem, portanto, os sujeitos estão em contínuo convívio, e a prática do bullying na escola pode ser apresentada como outro tipo de violência nos diversos contextos. Esse aspecto é apresentado por Albino e Terêncio (2012), que talvez a maioria dos pesquisadores não tenha atentado ao fato de que as causas do bullying podem estar em fatores econômicos, sociais, culturais, passando a considerar como naturais e independentes das contradições que os produziram. Isso resulta numa visão mais simplista e faz uma análise superficial da ação do bullying como apenas unidimensional.

Os informantes caracterizavam o bullying como algo muito complexo, que carrega uma pluralidade de sentidos e de uma instância mais subjetiva, pois o que uma pessoa entende como um ato de violência pode não ser percebido da mesma forma por outra já que "às vezes a pessoa fala pensando que não está ofendendo, mas está ofendendo sim". O bullying é uma forma de violência mais peculiar que muitas vezes passa de forma despercebida deixando marcas implícitas nas vítimas. De acordo com Martins e Almario (2012), os agressores apresentam tendências agressivas devido uma influência do seio familiar, visto que os pais fomentam mais atitudes hostis do que de afeto. Essas atitudes são direcionadas à vítima de agressão, e muitas vezes contam ainda com a participação indireta dos espectadores, contribuindo para a participação da prática de forma passiva. 
Em conformidade com os relatos, foi possível identificar que os jovens vivenciaram esse tipo de violência tanto no papel de agressor quanto de vítima. As atitudes de bullying dizem respeito a comportamentos propositais que acontecem com uma frequência e sem motivação aparente. Os casos mais comuns relatados referiam-se à aparência física, aos apelidos, ameaças, insultos, agressões físicas e verbais. Essas práticas habitam o cotidiano da cultura ordinária, caracterizadas como práticas dos não produtores. Geralmente nessa relação entre agressor e vítima, esta consegue pequenos sucessos, o que Certeau (2008, p.154) chama de golpes ou bricolagens, que são pequenas vitórias dos mais fracos sobre os mais fortes a partir de novas maneiras de fazer; já em outros casos isso não é possível.

Através da linguagem os informantes relatavam que a maior característica do bullying está relacionado ao fato de que quem pratica "quer ser considerado o bambambam do grupo", pois a pessoa que está desenvolvendo o bullying passa a ser idolatrado pelos demais, não medindo esforços para conseguir isso. Para Certeau (2008, p. 154), é através do conteúdo do relato que pode ser modificada a realidade, que desvia ou faz "golpe" por um passado e gera uma nova produção de sentido.

É preciso perceber que as práticas cotidianas também são esquemas, estruturas, que se desenvolvem de acordo com as circunstâncias, momentos, que definem as maneiras de usar palavras e as coisas. Certeau (2008, p. 92) explica que as "maneiras de fazer" e as maneiras de utilizar não são e nem poderiam ser repetições do que já está preestabelecido no social. A principal estratégia encontrada pelos jovens é através de uma nova maneira de pensar o cotidiano, percebendo que o ato de violência que você está cometendo com o outro é errado e tentar de alguma forma reparar o erro. Isso pode ser feito principalmente através das novas maneiras de fazer e utilizar as práticas culturais dos consumidores.

O diálogo, a compreensão dos sentidos dessa prática e os possíveis resultados que pode ocasionar ao indivíduo que sofre e ao agressor são algumas das medidas que os alunos consideram primordiais para suprimir o bullying. Outras táticas dos alunos consistiam em implantar programas preventivos e ações na escola, na família e na comunidade em geral, como forma de conscientizar sobre o que é o bullying, os âmbitos que perpassa e os prejuízos que a prática provoca nos indivíduos. Os alunos relatavam que talvez com essas provi- dências uma mudança na realidade escolar e a violência no contexto local não ficassem meramente no pensamento e sim mais perto de se concretizar.

De acordo com os jovens, torna-se viável pensar o cotidiano embora não dependa somente de uma dada população. Ao final das entrevistas os adolescentes retomaram sobre a violência na conjuntura nacional, ressaltando a falta de compromisso e descaso das instâncias governamentais para mudar o panorama atual. Essa realidade é deixada para segundo plano e progressivamente a incidência de violência aumenta. Os informantes não deixaram de fazer uma ligação direta com a situação de negligência e hostilidade por eles experienciadas, evidenciando a necessidade emergente de analisar a violência e os aspectos nela implicados.

A violência parece não ter um prazo de validade, porém os jovens revelaram que como primeiro passo é a mudança a partir de cada um, pois quando "eu penso diferente eu dou a oportunidade para que a pessoa pense também". Talvez com essa conscientização, a violência tenha um espaço de reapropriação e paulatinamente vá diminuindo. Ressaltam também a importância da participação popular quanto aos direitos e deveres enquanto cidadãos, solicitando ao Estado e às demais esferas de poder, políticas que visem a prevenção das ocorrências de ameaças e a promoção dos direitos de cidadania da população.

\section{Considerações finais}

A experiência de estágio somada à possibilidade de realizar entrevistas com os alunos que tive contato proporcionou momentos ricos de aprendizado e investigação. Percebi a amplitude de comportamentos e atitudes que existem no cotidiano. Desse modo, a cultura, o seio familiar, a escola, as vivências, seus meios sociais estão diretamente relacionados entre si, sendo praticamente impossível analisar as práticas cotidianas a partir de um discurso unilateral.

Ao longo do desenvolvimento do trabalho, fui percebendo os sentidos e significados que os informantes atribuíam à violência, a partir da observação participante da pesquisa, atentando aos detalhes implícitos e explícitos das falas como também assegurando à proteção necessária para os jovens no que se referia ao sigilo das informações.

A utilização do método da etnografia favoreceu na busca e tentativa de compreender a complexidade da realidade do local, tendo em vista alcançar os objetivos da pesquisa. A oportunidade de ter me inserido 
em uma realidade social diferente da que eu habitualmente estava acostumada, me fez mergulhar e aprender sobre outra cultura, contribuindo para reflexões acerca do fenômeno da violência.

A violência na perspectiva dos adolescentes traz consigo uma série de significações que envolvem todo o contexto social que dela fazem parte. A alternativa de pesquisar o cotidiano na perspectiva das práticas culturais de Certeau permitiram pensar a sociedade local como potente e transformadora através de táticas e estratégias dos sujeitos praticantes, de novas maneiras de fazer e como se utilizar daquela realidade para transformá-la.

Essa concepção permite que os jovens não sejam apenas meros consumidores e espectadores, que aceitam o que a sociedade as impõe, mas como sujeitos que questionam e refletem sobre o seu papel como sujeitos ativos para reapropriar os espaços a partir de novas maneiras de pensar e modificar o seu dia a dia. Através dessa prática, os jovens vão construindo outros modos de fazer e utilizar o conteúdo das práticas cotidianas, readaptando-as e as ressignificando.

Pensar o cotidiano e transformá-lo é ampliar o olhar para a pluralidade de práticas existentes nas relações que são manifestadas pela infinidade de conhecimentos, vivências, saberes e conflitos reelaborados, partilhados e modificados que tecem a complexidade do fazer. Essas invenções vão gerando uma nova "cultura" e novas maneiras de reorganizar as práticas cotidianas.

Assim, como afirma Certeau (2008, p.105) é preciso entender que "o estudo de algumas táticas cotidianas presentes não deve, no entanto, esquecer o horizonte de onde vêm e, no outro extremo, nem o horizonte para onde poderiam ir", ou seja, o estudo das táticas significa ver as coisas de uma maneira para outra, sendo passíveis de um caminho de investigação, descoberta e além disso de modificação na sociedade pelos sujeitos.

\section{Referências}

Abramovay, M., Castro, M. G.,Pinheiro, L. C., \& Martinelli, C. C. (2002). Juventude, violência e vulnerabilidade social na América Latina: Desafios para políticas públicas. Brasília, DF: Unesco.

Albino, P. L., \& Terêncio, M. G. (2012). Considerações críticas sobre o fenômeno do bullying: Do conceito ao combate e à prevenção. Revista Eletrônica do CEAF, 1(2). Recuperado de https://www.mprs.mp.br/media/areas/ biblioteca/arquivos/revista/edicao_02/vollno2art4.pdf

Bourdieu, P. (2011). A miséria do mundo (8a ed.). Petrópolis, RJ: Vozes.

Cerqueira, D., Lima, R. S., Bueno, S., Valencia, L. I., Hanashiro, O., Machado, P. H. G. et al. (2017). Atlas da violência. Brasília, DF: Instituto de Pesquisa Econômica Aplicada.

Certeau, M. (2008). A Invenção do cotidiano: 1. Artes de fazer. Petrópolis, RJ: Vozes.

Deepask (2016). Taxa de homicídios: Veja número de assassinatos por cidade do Brasil - TIMON, MA. Recuperado de http://www.deepask.com.br/goes?page=Confira-a-taxa-de-homicidios-no-seu-municipio

Dinis, N. F. (2011). Homofobia e educação: quando a omissão também é signo de violência. Educar em Revista, (39), 39-50. https://doi.org/10.1590/S0104-40602011000100004

Guareschi, N. M. F., Reis, C., Huning, S. M., \& Bertuzzi, L. D. (2007). Intervenção na condição de vulnerabilidade social: um estudo sobre a produção de sentidos com adolescentes do programa do trabalho educativo. Estudose Pesquisa em Psicologia, 7(1)

Instituto Brasileiro de Geografia e Estatística. (2016). Censo Demográfico de 2015. Brasília, DF: o autor. Recuperado de: ftp://ftp.ibge.gov.br/Estimativas_de_Populacao/Estimativas_2015/estimativa_TCU_2015_20170614.pdf

Kaefer, C. O., Traesel, E. S., \& Ferreira, C. L. (2010). A comunidade escolar como protagonista na prevenção da violência contra a criança e o adolescente. VIDYA, 30(2), 21-31.

Lustosa, P. R. (2013). Dispositivos socioeducativos, biopolítica e governamentalidade (tese). Faculdade de Ciências Humanas, Universidade Federal de Minas Gerais, Belo Horizonte, MG, Brasil.

Martins, N. V., \& Almario, A. (2012). Bullying: uma perspectiva sobre o agressor. Revista da Universidade Ibirapuera, 4, 17-21.

Passos, E., Kastrup, V., \& Escócia, L. (2014). Pistas do método da cartografia: Pesquisa-intervenção e produção da subjetividade (3a ed.). Porto Alegre, RS: Sulina. 
Toledo, L. G., \& Teixeira, F. S. (2013). Homofobia familiar: abrindo o armário 'entre quatro paredes'. Arquivos Brasileiros de Psicologia, 65(3), 376-391.

Waiselfisz, J. J. (2015). Mapa da violência 2015: Adolescentes de 16 e 17 anos do Brasil. Recuperado de http://www. mapadaviolencia.org.br/pdf2015/mapaViolencia2015_adolescentes.pdf

\section{Raquel da Silva Rodrigues}

Psicóloga pela Universidade Estadual do Piauí (UESPI). Teresina - PI. Brasil.

CRP 21/03009.

E-mail: raquel_rdsilva@hotmail.com

\section{Patrícia Rocha Lustosa}

Professora Adjunta da Universidade Estadual do Piauí (UESPI). Teresina - PI. Brasil. Pós-Doutorado em Sociologia pela Universidade do Porto (UPORTO). Porto. Portugal. Doutora em Sociologia pela Universidade Federal de Minas Gerais (UFMG). Belo Horizonte - MG. Brasil. Mestre em Psicologia pela Universidade Federal do Ceará (UFC). Fortaleza - CE. Brasil.

E-mail: plustosa@yahoo.com

Endereço para envio de correspondência:

Rua Olavo Bilac, 2335 - Centro (Sul), Teresina - PI, 64001-280

Recebido 19/07/2017

Reformulado 19/01/2018

Aprovado $31 / 01 / 2018$

Received 07/19/2017

Reformulated $01 / 19 / 2018$

Approved 01/31/2018

Recibido 19/07/2017

Reformulado 19/01/2018

Aceptado 31/01/2018

Como citar: Rodrigues, R. S., \& Lustosa, P. R. (2018). As táticas e estratégias de enfrentamento da violência entre jovens em Timon-MA. Psicologia: Ciência e Profissão, 38(4), 787-800. https://doi.org/10.1590/1982-3703002852017

How to cite: Rodrigues, R. S., \& Lustosa, P. R. (2018). Tactics and Strategies for Coping with Youth Violence in Timon-MA. Psicologia: Ciência e Profissão, 38(4), 787-800. https://doi.org/10.1590/1982-3703002852017

Cómo citar: Rodrigues, R. S., \& Lustosa, P. R. (2018). Las tácticas y estrategias de enfrentamiento de la violencia entre jóvenes en Timon-MA. Psicologia: Ciência e Profissão, 38(4), 787-800. https://doi.org/10.1590/1982-3703002852017 